\title{
Maternidades en disputa: E l país bajo mi piel y la apropiación del discurso ${ }^{1}$
}

\author{
Gema D. Palazón Sáez
}

Resumen:

El artículo busca dilucidar principalmente dos cuestiones en torno a la obra E 1 país bajo mi piel de G ioconda Belli: precisar cómo se construye el yo en un texto híbrido que mezcla memoria, autobiografía y testimonio, y analizar la función de subvertir el discurso patriarcal sobre la maternidad. En el primer punto, se observa que Belli forja un yo testimonial insoslayable de un yo poético; con ellos legitima su posición de sujeto frente a la historia reciente de Nicaragua, a través de la memoria y la reelaboración estética. En el segundo, se descubre que el discurso de Belli reformula retóricas de origen patriarcal para subvertirlas y reivindicar su papel como sujeto y tener un lugar en la historia de la revolución social nicaragüense. Resignificando el cuerpo femenino como discurso político, expone un "maternalismo" adaptado a un feminismo militante, y llevándolo del ámbito de lo privado a lo público.

Palabras clave:

G ioconda Belli, Novela nicaragüense siglo xx, texto híbrido, memoria, autobiografía, testimonio, historia reciente de Nicaragua, maternidad, cuerpo femenino, discurso patriarcal, feminismo.

${ }^{1}$ Agradezco a la Agencia Española de Cooperación Internacional y el Ministerio de Asuntos Exteriores Español, su compromiso y apoyo a mi proyecto, sin cuya colaboración no habría podido desarrollar éste y otros trabajos, como becaria del programa III-C MUTIS.

${ }^{*}$ Universidad Centroamericana de Managua. 


\title{
1. La construcción del yo: entre el testimonio, la autobiografía y la memoria
}

\author{
Esto es el exilio, \\ este tenerme que inventar un nombre, \\ una figura, \\ una voz nueva. \\ Este tener que andar diciendo \\ de dónde soy, qué hago aquí. \\ E x ilio, Gioconda Belli.
}

El texto que Gioconda Belli presenta en forma de memorias en El país bajo mi piel parece recorrer a modo de autobiografía los años que marcaron su vida como mujer, madre y revolucionaria. Me gustaría plantear una serie de interrogantes alrededor de su posición como mujer-testigo de los años que marcaron el devenir histórico de Nicaragua y que trataré de responder a lo largo de este texto. Al mismo tiempo, me interesa relacionar los hechos históricos relatados por Belli y el discurso de la maternidad que la autora esgrime en buena parte de su producción: ¿qué lecturas ofrece la consideración de El país bajo mi piel en su valor testimonial?,2 ¿qué construcción del yo se proyecta en sus memorias?, ¿de qué manera la representación sociocultural pesa sobre las mujeres que se rebelan contra el destino que el patriarcado y la biología dispone para ellas, y hasta dónde llega su trasgresión? Por último, ¿cómo entender ese discurso de la maternidad que en ocasiones es además maternalista con su feminismo militante?

Son estas cuestiones que me permitirán articular el complejo juego de lenguajes que se entrecruzan en el discurso de Gioconda Belli para apropiarse del mismo y que, recuperando la consigna de

${ }^{2}$ Se ha discutido mucho sobre la cuestión del testimonio en el caso de las memorias de Gioconda Belli, pues su propuesta no se adscribe a la categorización de los testimonios latinoamericanos de denuncia social que algunos autores han delimitado para los textos testimoniales de la segunda mitad del siglo XX en América Latina. Más adelante me ocupo de esta cuestión. 
"el cuerpo es político", pone en marcha toda una red de relaciones entre biología, lenguaje, poder, feminidad y discurso. D aisy Z amora, refiriéndose a la producción de Belli, afirma que "un texto es cuerpo, es habla, es posición" y, en este sentido, "el producto de tal actividad ingresa en relación de inserción con el sistema dominante, que en parte coincide con él y en parte lo erosiona o lo desborda" (L a mujer nicaragüense en la poesía. A ntología 50 ). E l país bajo mi piel ingresa así en esta encrucijada en la que Belli ha forjado su yo poético y, por extensión, su yo testimonial; ambos la legitiman para dar cuenta de los acontecimientos que, como sujeto, determinaron su posicionamiento ético y estético frente a la historia reciente de Nicaragua.

El texto de Belli ha suscitado algunos debates alrededor del interés de buena parte de la crítica en inscribirlo en la "tradición del testimonio latinoamericano". ${ }^{3}$ En este sentido, autores como José María Mantero ${ }^{4}$ han señalado el posible valor anti-testimonial del texto bajo los parámetros de la definición de testimonio de Beverley, para quien supone "una narrativa contada en primera persona por un narrador que es además el protagonista o testigo del hecho que

${ }^{3}$ Utilizo el entrecomillado porque lo que cuestiono aquí es precisamente si existe un testimonio latinoamericano. D esde los Estudios Culturales, sobre todo desde el campo de la crítica de Estados Unidos, se ha venido desarrollando en los últimos años un particular interés por este aspecto y se ha articulado todo un aparato crítico especialmente interesado en ubicar los testimonios latinoamericanos de la segunda mitad del siglo veinte y categorizarlos en una suerte de canon que, a mi juicio, puede ser cuestionado. Para profundizar en esta cuestión pueden consultarse, entre muchos otros, los trabajos de Mabel Moraña ("El boom del subalterno" en Teorías sin disciplina [latinoamericanismo, poscolonialidad y globalización en debate], Proyecto Ensayo Hispánico, 1998), John Berveley (The real thing: testimonial discourse and L atin A merica, D uke University Press, D urham, 1996), Elzbieta Sklodowska (E 1 testimonio hispanoamericano, Peter Lang, New York, 1992), etc.

${ }^{4}$ Mantero, José María, "E l país bajo mi piel de G ioconda Belli como anti-testimonio" en Revista Istmo, Revista virtual de estudios literarios y culturales centroamericanos, $\mathrm{n}^{\mathrm{0}}$ 6, julio-diciembre de 2003. 
cuenta" y además con "una urgencia de comunicar un problema de represión, pobreza, subalternidad, encarcelamiento, lucha por la supervivencia" (The real thing: testimonial disoourse and Latin A merica 24), basándose por tanto en una definición del testimonio que lo sitúa en su solidaridad con la comunidad en contextos de violencia de Estado en el caso latinoamericano. Belli parece alejarse de la definición de Beverley porque la excepcionalidad de su testimonio no refiere tanto a los hechos contados (que en sí lo fueron, pero E 1 país bajo mi piel no se centra en ellos), sino a la del propio sujeto enunciador. Éste ha sido uno de los aspectos más problemáticos que la crítica ha planteado al abordar el texto, puesto que a diferencia de otros textos testimoniales centroamericanos, Belli no parece dar cuenta de ninguna colectividad y su posicionamiento oscila entre la creación poética de sí misma y la experiencia novelada de su militancia durante los años de revolución. ${ }^{5}$

El subtítulo del libro, M emorias de amor y guerra, fija los dos ejes que atraviesan todo el discurso como motores de la transformación en el sujeto que se construye además desde la selección que la memoria impone y que Belli reformula. Por otra parte, la autora reconoce claramente el destinatario y el sentido de su propósito en la entrevista que concedió a Radio Primerísima con motivo de la presentación del libro en Nicaragua. Belli declara haber tenido presente no cuál quería que fuera su testimonio de la experiencia revolu-

${ }^{5}$ Hay un aspecto muy interesante en la lectura de las memorias de Belli en el que no puedo entrar aquí. Se trata precisamente del lugar que ocupa su testimonio dentro de la tradición nicaragüense de los años ochenta y noventa. El texto de Belli parece incluirse como una secuela dentro de dicha tradición al tiempo que mantiene una relación problemática con su carácter autobiográfico por el conflictivo lugar desde el que Belli se sitúa. El suyo es un espacio de indeterminación entre la reivindicación personal, el prestigio literario y la confesión de una vida en el que se ponen en juego sus orígenes burgueses, sus años de lucha en el exilio, su reconocimiento como escritora y su situación actual en uno de los barrios más lujosos de Los Ángeles. Para abordar esta cuestión, puede consultarse el texto de Nicasio Urbina "Las memorias y las autobiografías como bienes culturales de consumo" (en Istmo. Revista virtual de estudios literarios y culturales centroamericanos, $n-11$, julio-diciembre de 2005). 
cionaria, sino qué le interesaría saber al potencial público lector de su personalidad pública. Sus memorias se convierten así en el testimonio novelado de sí misma y la revolución sandinista. Es esa misma construcción la que determina que El país bajo mi piel siga conteniendo una fuerte carga poética y literaria que le permite asegurar que es su mejor obra "desde el punto de vista literario". La imbricación estética y el valor literario que Belli otorga a sus memorias son por tanto el punto de partida desde el que se configura su yo testimonial. Al mismo tiempo, su particular representación de la Mujer vinculada permanentemente a la Naturaleza ${ }^{6}$ forja su posición ética en el campo literario y su lucha revolucionaria.

\section{Las grietas del discurso: cuando la mujer se apropia del lenguaje}

"Qué resistentes somos las mujeres. Q ué increíble, maldita resistencia tenemos las mujeres".?

"D os confusiones que a la mujer le dan la sensación de ser más cuerpo que los demás: su cuerpo que acaba encontrándose en otros cuerpos y su vida que se confunde con el dar la vida" (Bocchetti 76).

En muchos aspectos, El país bajo mi piel presenta discursos aparentemente contradictorios. Mientras Gioconda Belli conquistó

${ }^{6}$ Para una mayor aproximación a este campo, puede consultarse el trabajo de Alejandra Aventín sobrela producción poética de G ioconda Belli, en el que explora las relaciones entre Naturaleza, cuerpo y Mujer en el caso de la autora nicaragüense.

${ }^{7}$ Belli, Gioconda, El país bajo mi piel. M emorias de amor y guerra, Plaza \& Janes, Barcelona, 2001. En adelante y para referirme a esta obra, citaré exclusivamente con el número de página entre paréntesis seguido de la cita. 
cuotas de poder y autonomía personal durante su militancia en el Frente Sandinista de Liberación Nacional, y se entregó gustosa a la ruptura de las normas sociales de la burguesía nicaragüense, que la condenaban al matrimonio y la maternidad sin mayores pretensiones que las de colmar esas dos experiencias bajo los marcos estructurales de la familia patriarcal, Belli no deja de representar ese universo simbólico del patriarcado que dota a la mujer de poderes misteriosos, extraños artificios para malear al hombre con sus "armas de mujer" y recupera buena parte de los mitos asociados a la maternidad construidos culturalmente (sobre la base de la religión, la política, la economía y la estructura social de la familia patriarcal). José María Mantero ha señalado que "lo que se encuentra en el texto de Belli es un continuo baile de construcción y desintegración entre sus orígenes burgueses y sus ideales revolucionarios, un baile que sigue hasta hoy día" (Mantero), como si estos dos discursos que se encuentran con frecuencia entre las páginas de $\mathrm{E} l$ país bajo mi piel discutieran abiertamente sin plena conciencia de la autora. Creo sin embargo que dicha dialéctica, obviamente visible en el texto, obedece en realidad a otro propósito más allá de la difícil coexistencia de ambos discursos que pretendo desarrollar bajo la forma de "grietas" en el discurso, este no es otro más que el discurso patriarcal, y la apropiación que Gioconda Belli lleva a cabo de su lenguaje.

Belli inicia sus memorias magnificando el poder misterioso del útero materno cuando reconoce su destino a partir del momento en el que a su madre se le presentó el parto:

Quizás porque mi madre sintió mi urgencia de nacer cuando estaba en el Estadio Somoza en Managua viendo un juego de béisbol, el calor de las multitudes fue mi destino [...] Quién sabe qué señales se transmitirían en el líquido amniótico, pero en vez de terminar como deportista con un bate en la mano, terminé esgrimiendo todas las armas a mi disposición para botar a los herederos del señor del caballo y participar en la lucha de mi país por liberarse de una de las dictaduras más largas del continente americano. (11) 
Es éste el comienzo de una larga sucesión de partos, renaceres y alumbramientos a veces físicos, a veces simbólicos, pero siempre con la mujer como sujeto engendrador ya sea vientre nutricio, tierra germinada o nueva conciencia. Belli diseña además un particular marco para sus memorias en un aspecto doble: la presentación y la secuencia. En la estructura narrativa, reproduce el esquema del Q uijote, ${ }^{8}$ llegando a identificarse con una quijota en distintos momentos del texto, exaltando así su individualidad y remarcando su posición de subalterna frente al discurso hegemónico. En este sentido, E l país bajo mi piel entra en contacto con lo que Mabel Moraña ha denominado "el boom del subalterno" y que caracteriza como un "fenómeno de diseminación ideológica de una categoría englobante, esencializante y homogenizadora por la cual se intenta abarcar a todos aquellos sectores subordinados a los discursos y praxis del poder". El texto de Belli incide en la consideración de subalternidad del sujeto que escribe (una mujer), al tiempo que reivindica un espacio en el circuito intelectual internacional propio, logrado a través del éxito editorial.

Belli parece bailar constantemente entre el rechazo y la escisión de su propia subalternidad. En el orden secuencial, rompe con el hilo cronológico lineal para hacer estallar de forma narrativa su propia experiencia fragmentaria como sujeto que afirma haber lidiado con distintas vidas, al tiempo que nos propone una lectura en paralelo de las mismas:

He sido dos mujeres y vivido dos vidas. Una de mis mujeres quería hacerlo todo según los anales clásicos de la feminidad:

${ }^{8}$ También su estructura responde a la de las C rónicas de Indias que los españoles dedicaran al "descubrimiento" de América Latina. D el mismo modo que Colón o Cortés se apropiaron del espacio, Belli se apropia de la historia reciente de Nicaragua y la transforma también volviéndola corporalidad viva, cubriendo esos años desde su subjetividad, identificándose y describiendo Nicaragua con cuerpo de mujer, construyendo en definitiva un concepto de nación que pasa por la feminidad de quien lo enuncia. 
casarse, tener hijos, ser complaciente, dócil y nutricia. La otra quería los privilegios masculinos: independencia, valerse por sí misma, tener vida pública, movilidad, amantes. (12)

Pero no sólo eso, ya que en la disociación entre sus roles sociales, las demandas histórico-culturales, su compromiso con la revolución y su deseo, han mediado también la escisión geográfica, el exilio, la clandestinidad y el descubrimiento de nuevas esferas aparentemente prohibidas para su sexo.

El punto de partida de Belli para esta disociación encuentra su centro en sus contradicciones para conciliar la lectura tradicional de la feminidad que su clase le imponía (y ella asume en su discurso en determinados momentos) y sus aspiraciones individuales que trataban de conquistar nuevos espacios desde el escenario revolucionario de Nicaragua en los años ochenta. Como límite de tal debate, Belli llegará afirmar "Sin renunciar a ser mujer, creo que he logrado también ser hombre" (12). De este modo, la autora deconstruye el modelo patriarcal hegemónico, apropiándose de su discurso y exhibiendo sus atributos como una nueva forma de subversión en el lenguaje. ${ }^{9}$

Es a raíz de este proceso que Belli despliega su discurso "maternalista" para asegurarse un lugar en la revolución. En E l país bajo mi piel se apropia de la geografía y de la historia de Nicaragua como ha hecho también en su poesía. El perfil de Nicaragua responde siempre a un cuerpo de mujer y a una naturaleza salvaje; la revolución fue engendrada también en el vientre femenino de la nación: "viví el embarazo y el parto de una criatura alumbrada por la carne y la sangre de todo un pueblo" (13), extendiendo así el vínculo materno de la mujer al resto de la sociedad en un nuevo

${ }^{9}$ A unque éste es un aspecto que se inicia en su producción poética, lo cierto es que en E l país bajo mi piel arguye las mismas estrategias para posicionarse como sujeto-mujer y como treta para convertir su militancia en algo más que pura representatividad o compromiso político. Es como si al margen de la revolución sandinista, Belli buscara los cauces de su propia revolución. 
tránsito de lo privado a lo público. Su experiencia de la revolución queda pues ligada a su feminidad y es desde ese discurso maternalista desde el que se acerca a la teoría de la Diferencia: "Yo era mujer. En el género humano la única que podía dar vida, la designada para continuar la especie [...] pero el [cuerpo] de la mujer, por su misma función, era más bello y asombroso" (45). De modo que lo que a lo largo de la historia nos ha estigmatizado y respondido al poder hegemónico para quedar ligadas a la representación de dualidades tales como pureza/ impureza, amor/ histeria, divinidad/ pecado, relegadas a la función biológica de la reproducción y sometidas a la identificación con la pulsión irracional de la Naturaleza, a Belli le sirve para reivindicarse como cuerpo femenino sobre los designios patriarcales.

E l país bajo mi piel decide hacer públicos los procesos privados de la mujer recorriendo desde la menstruación hasta el parto, pasando por el deseo, el erotismo y el amor en tiempos de guerra al tiempo que los transforma y resignifica frente a la moral hegemónica, los hace ser compañeros en la lucha revolucionaria porque: "rodeada de olor a pañales y el llanto de los cólicos de Melissa, apaciguando los celos de Maryam [...] armé mi primera red de colaboradores" (91). Ambos mundos confluyen así en una realidad a veces desquiciante para la autora, rechazando frontalmente aquella lectura que expulsa esa experiencia al ámbito de lo privado: "nunca olvidaré la experiencia surrealista de esas largas discusiones sobre cómo hacer frente a los berrinches infantiles, las preguntas de los hijos 0 las limitaciones de tiempo. Trataba de concentrarme, de ser una más de aquellas mujeres" (113).

A pesar de ello, su construcción vuelve a quedar sujeta al modelo tradicional con el discurso más conservador, a veces lapidario, al que pretende hacer frente. Considerar su sexo como recipiente del misterio revelado exclusivamente a las mujeres y rebelarse contra las imposiciones sociales no impidieron que aceptara las leyes del traspaso patriarcal del padre al esposo y reconocerse adulta después de haber sido desposada y haber consumado el matrimonio. Belli mantiene constantemente la tensión entre el modelo de feminidad claramente patriarcal y su deseo de subvertir el orden del 
discurso a partir de ese mismo lenguaje. Consuelo Meza resuelve esta tensión y establece el origen de estas contradicciones en la propia condición de las escritoras centroamericanas:

las escritoras contemporáneas se ven obligadas a negociar continuamente con los elementos tradicionales de autorrepresentación femenina correspondientes al modelo 'Mujer' y también con aquellos modelos nuevos que reflejan su experiencia femenina como sujeto.

Sobre la base de esta contradicción aparente, Belli encuentra las fisuras de desestabilización del discurso dominante. Su continuo ir y venir sobre su origen burgués y el despertar de una suerte de "conciencia de sí" devienen en la búsqueda incesante de su propio deseo y satisfacción individual. Es ese mismo deseo el que la lleva a convertirse en una esposa adúltera y recuperar 0, más bien reivindicar por primera vez, su autonomía como sujeto: "Esa transgresión fue mi Big Bang personal. Me hizo cuestionar mis deberes y considerar mis derechos, lo que era mi vida y lo que podía ser" (58-59). La conciencia de haber roto el vínculo sagrado del matrimonio, de sentirse una auténtica Eva más allá de las doctrinas religiosas que recibiera en La Asunción y el hecho de que su trasgresión estuviera vinculada además a los misteriosos e innatos poderes de seducción que se atribuyen a las mujeres, son cuestiones que se entretejen para dar cabida a la emergencia de ese nuevo discurso que reivindica a Eva, a la Manazana, a Helena: "D ecidí descifrar las mitologías que atribuían a mi género el caos, el fin de la racionalidad, la capacidad de provocar guerras y cataclismos universales con el mordisco a una manzana o el desastre de una sandalina" (199) y transforma la feminidad en una nueva suerte de divinidad creadora: "dentro de mí empezaron los siete días de la creación, los volcanes, los cataclismos" (59). Para Belli, este discurso también reviste la maternidad de nuevos significados más allá del hogar familiar, para extender su poder más allá del ámbito de lo privado. 


\section{Conclusiones}

En 1981, el programa del Centro Cultural Virginia Wolf se inauguraba con un texto de Alexandra Bocchetti que reflexionaba sobre el ambiguo materno en tanto las mujeres llevan escrita la pérdida de sí como condición existencial por la experiencia de la maternidad, que hace que el cuerpo de la mujer se extienda más allá del propio hasta apresar también el de los hijos después del parto, porque a diferencia del mundo animal, "lo materno humano dura toda una vida" hasta convertirse para las mujeres, sean madres 0 no, en la única modalidad posible de relación con los otros. Veinte años después, Belli reformula su experiencia de los tiempos de la revolución a través de la extensión de esa "pérdida de si" al servicio de la transformación en Nicaragua y como propuesta de nuevos lugares de enunciación para las mujeres:

Las mujeres han estado operando desde el principio del cuido a lo largo de la mayor parte de nuestra historia. Estamos entrenadas a cuidar y nutrir a los demás. Y en vez de ver esto como una desventaja - como nuestra capacidad de dar a luz ha sido convertida en una desventaja- deberíamos ser capaces de generar y socializar un nuevo tipo de ética, nuevas reglas del juego. (Randall 263)

Ante la lectura patriarcal de la maternidad, que la limita a la crianza y destina a la mujer al espacio de lo doméstico, Belli se revela cuando su marido la acusa de "mala madre" bajo estos mismos esquemas por la violación primordial del supuesto instinto maternal que hace de la mujer-madre un ser dependiente de sus hijos. Reconoce tener más aspiraciones que las de dedicarse a ser una madre nutricia confinada en el hogar, pero ante su propia experiencia de la maternidad los estigmas de siglos de dominación asoman de nuevo. La propia Belli se siente víctima de esta lectura que está interiorizada en las mujeres cuando se separa de su hijo ante el reclamo de su segundo marido: 
La Maligna, Circe, la Medusa era yo [...] La culpa, siglos de mujeres adúlteras apedreadas, la educación cristiana, me impedían ver otra responsabilidad que no fuera la mía. Me paralizó el temor de no ser una madre adecuada para Camilo, mi inconsciente aceptó los prejuicios contra mi propio género. (339)

Pero no fueron sólo las ataduras históricas y sociales asignadas a su sexo las que ponen en jaque el discurso de Belli en determinados momentos de sus memorias. Su propia militancia y la lealtad al Frente Sandinista que bajo su estructura abierta seguía manteniendo una férreajerarquía masculina y pensada para hombres hicieron que Belli hablara después del fracaso de la revolución como una suerte de "machismo político". Cuando se convierte en la delegada de prensa para el extranjero y su relación con un periodista estadounidense no es aprobada por las cúpulas del Frente, Belli recibe presiones hasta tener que decidir entre lo público o lo privado. Las dudas suscitadas alrededor de su militancia y su capacidad de discreción le hicieron escoger ser "hombre nuevo" y no "mujer emotiva" para conseguir la aprobación en un mundo nuevamente de hombres que valoraba de forma limitada la participación de la mujer.

A pesar de que la Revolución Sandinista incorporó a la mujer rápidamente al proceso revolucionario, en muchas ocasiones se ha hecho notar, sobre todo durante los noventa, la doble moral de su discurso emancipador. ${ }^{10} \mathrm{Si}$ bien es cierto que reconocieron el papel de la mujer y la reclutaron en sus filas, en el primer gobierno sandinista no figuraba ninguna mujer y algunas de las reservas que se tenían hacia las que consiguieron ciertas cuotas de poder no se reproducían en la jerarquía masculina.

Belli, a pesar de todo, en su intento por reivindicar su contribución y difundir su propia lectura del proceso revolucionario cuando llega a Managua tras el triunfo sandinista, vuelve a feminizar su

${ }^{10}$ Los testimonios y las entrevistas recopilados por Margaret Randall son una buena muestra de ello. 
discurso desde la concepción maternalista capaz de abarcar toda una nación: "Ese viaje lento del camión hasta el centro de Managua tuvo para mí sabor a parto, a recompensa final del dolor. Nacía mi país. Reía" (326).

La ironía de la historia quiso que después, en los noventa, durante la campaña electoral fueran dos cosmovisiones patriarcales en el campo de la representación simbólica las que se enfrentaran en la lucha por el acceso al poder: el gallo peleador de los sandinistas y la imagen de una Violeta Chamorro que queda definida en $\mathrm{E} l$ país bajo mi piel como "una figura maternal" en un sentido mariano.

E l país bajo mi piel se construye así como un texto que reconcilia a Belli con su propia experiencia, sin renunciar a la recreación retórica que su posición como escritora consagrada le permite. Belli afirma que la poesía, el compromiso político y la conciencia de su "poder femenino" entraron a su vida de forma simultánea, es por eso que su recuperación de los años de lucha y la trayectoria hasta su tranquila casa de Santa Mónica están recorridas por el lenguaje poético y la magia, las pasiones de su vida y la determinada lucha por un proyecto que pretendía transformar todo un país y que ella quiso que tuviera signo de mujer.

\section{Bibliografía}

Aguirre, Erick. Subversión de la memoria. Tendencias en la narrativa centroamericana de postguerra. Managua: Ediciones del Centro Nicaragüense de Escritores, 2005.

Aventín, Alejandra. Insurrecciones del verbo en la posmodernidad: la voz poética de G ioconda Belli y A na Istarú, (trabajo de investigación inédito).

Belli, Gioconda. E l país bajo mi piel. Memorias de amor y guerra. Barcelona: Plaza \& Janes, 2001.

Beverley, John. The real thing: testimonial disoourse and L atin A merica. D urham: Duke University Press, 1996.

Bocchetti, Alexandra. L o que quiere una mujer. Madrid: Cátedra, 1999. 
D elgado, Leonel. "Proceso cultural y fronteras del testimonio nicaragüense." Istmo. Revista virtual de estudios literarios y culturales centroamericanos, nำ11, julio-diciembre de 2005, <http:/ / www.wooster.edu/ istmo/ articulos/ proceso.html> consultado el 8 de noviembre de 2005.

Ferro, Norma. El instinto maternal o la neosidad de un mito. Madrid: Siglo XXI, 1991.

Mackenbach, Werner. "Realidad y ficción en el testimonio centroamericano." Istmo. Revista virtual de estudios literarios y culturales centroamericanos, no11, julio-diciembre de 2004, <http:/ / www.wooster.edu/ istmo/ articulos/ realidad.html> consultado el 8 de noviembre de 2005.

Mantero, José María. "El país bajo mi piel de Gioconda Belli como anti-testimonio." Istmo. Revista virtual de estudios literarios y aulturales centroamericanos, n6, julio-diciembre de 2003, <http:/ / www.denison.edu/ collaborations/ istmo/ n06/ articulos/ pais.html> consultado el 8 de noviembre de 2005.

Meza, Consuelo. "Panorama de la narrativa centroamericana de mujeres." Istmo. Revista virtual de estudios literarios y culturales centroamericanos, $\mathrm{n}^{\mathrm{0}}$ 4, diciembre de 2002, <http:/ / www.denison.edu/ collaborations/ istmo $\mathrm{n} 04 /$ proyectos/ panorama.html > consultado el 8 de noviembre de 2005.

Montenegro, Sofía. La revolución simbólica pendiente. M ujeres, medios de comunicación y política. Managua: Centro de Investigaciones de Comunicación (CINCO), 1997.

Moraña, Mabel. "El boom del subalterno." Teorías sin disciplina (latinoamericanismo, posoolonialidad y globalización en debate). Proyecto Ensayo Hispánico, 1998, <http:/ / www.ensayistas.org/ critica/ teoria/ castro/ Mabel.htm> consultado el 8 de noviembre de 2005. Randall, Margaret. L as hijas de Sandino. U na historia abierta. Managua: Anama, 1999.

Sklodowska, Elzbieta. E 1 testimonio hispanoamericano. New York: Peter Lang, 1992.

Solà, Roser y Trayner, Ma Pau. Ser madre en N icaragua. Testimonios de una historia no escrita. Barcelona: Icaria Editorial, 1988.

Tubert, Silvia, ed. Figuras de la Madre. Madrid: Cátedra, 1996. 
Urbina, Nicasio. "Las memorias y las autobiografías como bienes culturales de consumo." Istmo. Revista virtual de estudios literarios y aulturales centroamericanos, n-11, julio-diciembre de 2005, <http// www. denison.edu/ collaborations/ ismo/n08/articulos/ memrias.html> consultado el 8 de noviembre de 2005.

Zamora, D aisy. L a mujer nicaragüense en la poesía. A ntología. Managua: Nueva Nicaragua, 1992. 